\title{
As formas de manifestação da privacidade nos três espíritos do capitalismo: da intimidade burguesa ao exibicionismo de si nas redes sociais
}

MARIANA ZANATA THIBES"

\section{Resumo}

A partir da articulação dos modos de vivência da privacidade em cada espírito do capitalismo, argumentamos que as transformações relativas à privacidade, comumente atribuídas à disseminação das novas tecnologias da informação e comunicação, só podem ser devidamente compreendidas a partir da ampliação do olhar à procura dos processos sócio-históricos que delimitam as fronteiras entre o público e o privado. Ao fazer isso, podemos perceber como os valores e justificações, que animam o capitalismo conexionista e promovem uma aproximação inédita entre a vida privada e o trabalho, redefinem os limites que separam a vivência íntima e privada da esfera da economia.

Palavras-chave: Privacidade; Espírito do capitalismo; Capitalismo Conexionista; Trabalho; Novas Tecnologias da Informação e Comunicação

\footnotetext{
"Pontifícia Universidade Católica de São Paulo, PUC/SP, Brasil
} 


\title{
The forms of expression of privacy in the three spirits of capitalism: from bourgeois intimacy to self-exhibitionism in social networks
}

\begin{abstract}
Based on the articulation of modes of experience in the private sphere in each spirit of capitalism, we argue that the contemporary transformations of privacy, commonly attributed to the spread of new information and communication technologies, can only be properly understood if we expand the gaze in search of socio-historical processes that define the boundaries between the public and the private. By doing this, we can see how values and justifications that animate the connectionist capitalism and promote an unprecedented rapprochement between private life and work, redefine the boundaries that separate intimate and private experience from the economic sphere.
\end{abstract}

Keywords: Privacy; Spirit of Capitalism; Connectionist capitalism; Labor; New information and communication technologies 


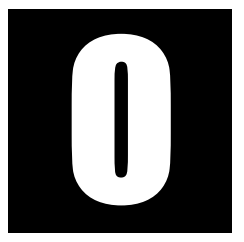

s momentos históricos marcados por importantes revoluções tecnológicas guardam entre si a semelhança de possuírem uma dupla natureza. Se, por um lado, são emblemas da inovação e dos prodígios humanos, da superação de limites e do controle e racionalização dos aspectos contingentes da vida, por outro, introduzem uma série de efeitos turbulentos à vida das pessoas. Nas palavras de Nicolau Sevcenko, "os novos recursos técnicos, por suas características mesmo, desorientam, intimidam, perturbam, confundem, distorcem, alucinam" (Sevcenko, 1998, p. 516). Não raro, seus efeitos perturbadores excedem aqueles de harmonização, daí que um olhar desavisado possa ser seduzido pela novidade que trazem, ao invés de perceber o desconforto e as tensões inevitáveis que as inovações tecnológicas produzem nos modos de vida.

A introdução da Internet e das novas tecnologias da informação no cotidiano certamente pode ser lida nesse registro. A despeito de seu potencial extraordinário de disseminar informações e ampliar os canais de comunicação, ela trouxe consigo uma série de efeitos turbulentos. Entre eles, os que despertam maior preocupação no presente são as ameaças à privacidade, em razão do potencial cada vez maior de coleta de dados e informações pessoais desses novos artefatos. No entanto, quando tratamos das consequências de uma mudança das condições materiais de reprodução do cotidiano há que se ter cuidado com o excesso de confiança em suas ilações. O entusiasmo acerca das inovações tecnológicas facilmente pode se reverter em seu oposto, isto é, na exagerada atribuição de diversos malefícios presentes à sua influência, quando, em realidade, as tensões resultam de longos processos que somente podem ser observados quando se amplia o intervalo do olhar. Nesse sentido, os fenômenos que denunciam a perda progressiva da privacidade e cuja causalidade se atribui, sem o peso da dúvida, às inovações tecnológicas 
teriam, como procuraremos mostrar, um prelúdio mais antigo do que a introdução das novas tecnologias da informação no cotidiano de boa parte da população mundial.

É evidente, porém, que, sem tais tecnologias, muitas das ameaças presentes à privacidade não existiriam. Contudo, o que sugerimos aqui é que o fenômeno percebido como a decadência da privacidade seja lido como a culminação, acelerada pela tecnologia, de um processo social bem mais antigo e amplo que a Internet e as NTICs.

É para compreender, portanto, um processo que se anuncia ao longo do desenvolvimento histórico, que procuramos recuperar, aqui, o conceito de "espírito do capitalismo". Trazido à luz em 1904, por Max Weber, e colocado entre aspas no título do livro "A ética protestante" e o espírito do capitalismo, ele é assim apresentado, como observa Pierucci, para indicar ao leitor de que se tratava de um "novo objeto de análise na busca sociológica de uma relação causal histórica" (Pierucci, 2004, p. 7). E o novo objeto não era o capitalismo como sistema econômico ou modo de produção e sim o capitalismo enquanto "espírito", isto é, cultura capitalista moderna tal como vivenciada pelas pessoas; em suma, "o capitalismo como conduta de vida" (idem, p. 7).

O longo processo histórico de mudança de mentalidades, condutas e valores, cuja materialização ou desfecho Weber localiza nas disposições específicas dos ascetas puritanos dos séculos XVI e XVII, é sintetizado na figura conceitual do espírito do capitalismo - a conclusão lógica de um longo desenvolvimento histórico, de um processo de racionalização religiosa que desemboca numa mudança tão significativa a ponto de transformar o "espírito" de toda uma época. Entretanto, sendo este um conceito histórico-desenvolvimental cujo conteúdo substantivo é datado, há que se perguntar sobre o modo de tratá-lo no presente. Trabalho importante e notório nesse sentido foi realizado pelos sociológos franceses 
Luc Boltanski e Eve Chiapello em O Novo Espírito do Capitalismo (2009). Inspirados diretamente no livro célebre de Weber, mas também nos trabalhos do sociológo Albert O. Hirschmann (1977), cuja tese oferece um bom modo de pensar acerca das justificações - questão de longa data na obra de Boltanski - para as práticas capitalistas, não apenas em termos das motivações das condutas individuais, mas em termos de justificações que orientam a ideia de bem comum e de coletividade (Du Gay; Morgan, 2013). Assim, para Boltanski e Chiapello (2009), a ideia de "espírito" aparece como a força que adentra o senso que os atores têm de si mesmos como tipos particulares de pessoas, e que anima as práticas, as instituições, orienta as regras de conduta, assim como certos discursos de legitimação que explicam, normalizam e motivam os atores. Acreditamos que esse modo de apreensão do conceito seja extremamente prolífico para pensarmos o modo como a privacidade se configura no presente. Ele nos encaminha para uma perspectiva sócio-histórica de longo alcance, que procura trazer à luz as transformações que a vida privada sofreu em cada espirito do capitalismo, até culminar em um tipo de "espírito" que não apenas transforma os sentidos originários da privacidade, como põe em xeque sua própria possibilidade de existência. Argumentamos que a decadência da privacidade, comumente atribuída ao desenvolvimento de artefatos tecnológicos com alta potência de vigilância, assim como ao surgimento de formas de interação virtuais nas quais a exposição da vida privada é vigorosa, é fruto de um processo histórico mais amplo, que pode ser buscado nas transformações dos sentidos que a vida privada assume em determinada época. Embora essa perspectiva nos faça deslizar por um campo maior de abstrações, ela carrega o potencial de ampliar o olhar para estabelecer articulações mais acertadas do que aquelas que o olhar fixado no presente é capaz de realizar. O leitor atento também perceberá que tomar como objeto a vida privada a partir de um escopo 
tão amplo, obriga-nos, assim como a outros autores que se aventuraram sobre o tema ${ }^{1}$, a sobrevoar períodos e territórios distintos, cuja relação pode parecer urdida de modo artificial, sobretudo quando feita no espaço limitado de um artigo. Quanto a isso, é preciso relembrar que a noção de espírito do capitalismo, aqui retomada, é que nos guiará nesses sobrevoos. Assim, notar-se-á que, se o primeiro espírito é majoritariamente calcado nos desenvolvimentos do capitalismo industrial europeu, sobretudo na França e na Inglaterra, no segundo, as descrições concentram-se nas transformações da sociedade norte-americana, enquanto no terceiro espírito, por se tratar já de uma sociedade globalizada, pode-se prescindir de tal precisão geográfica. Esse locais podem ser considerados os pólos irradiadores do "espírito" em cada momento, embora isso não queira dizer que somente nesse lugares ele tenha estado presente ${ }^{2}$.

\section{As origens do direito de privacidade}

Um dos documentos considerados fundadores do direito de privacidade moderno foi escrito em 1890, nos Estados Unidos, pelos juristas Samuel Warren e Louis Brandeis. O mote que deu origem ao artigo foi a percepção de que os desenvolvimentos no mundo dos negócios e as novas invenções técnicas, bem como uma nova forma de vivência na esfera privada criaram a necessidade de ampliação do escopo dos direitos civis para proteção da esfera doméstica ou privada. Para desenvolver seu argumento, os autores partem de uma analogia com o direito de pro-

\footnotetext{
${ }^{1}$ Cf. Vainfas, Ricardo. História da vida privada: dilemas, paradigmas, escalas. Anais do Museu Paulista. São Paulo. N. Sér. v.4 p.9-27 jan./dez. 1996.

${ }^{2}$ A própria discussão e os processos que instauram o direito de privacidade ocorrem simultaneamente na Europa, sobretudo na Inglaterra, e nos Estados Unidos. Entretanto, o documento produzido pelos juristas norte-americanos Warren e Brandeis, em 1890, adquiriu grande notoriedade e traz elementos muito importantes para compreender essa gênese, e é por isso que decidimos utilizá-lo aqui.
} 
priedade, tanto para mostrar as semelhanças com a privacidade quanto para estabelecer as especificidades do último. De acordo com os juristas, o reconhecimento da natureza espiritual do homem, de seu intelecto e seus sentimentos, tornou necessária a expansão da concepção legal de propriedade para abarcar também as formas de posse intangíveis, já que, naquele momento, claro estava que "apenas uma parte da dor, do prazer e do lucro residiam nas coisas físicas" (Warren; Brandeis, 1890, p. 1-2, tradução minha).

Sendo os objetos da privacidade - a esfera doméstica e sua personalidade - propriedade dos indivíduos, não estariam já protegidos pelos direitos de propriedade intangível? Warren e Brandeis perceberam, entretanto, que havia uma diferença entre os direitos de propriedade (tangível e intangível) já existentes e a privacidade, isto é, de que esta última não era simplesmente mais uma forma de propriedade como qualquer outra, fato que impossibilitava sua consideração equivalente.

Desse modo, embora a vida privada fosse propriedade do indivíduo, havia nela algo de específico que a ideia de propriedade simples já não era capaz de abarcar. Essa especificidade, captada pelos autores, diz respeito à diferença entre a casa como propriedade privada do indivíduo, e a casa como "lar", esfera doméstica e recinto de um tipo de existência distinta da que havia no espaço público. A partir dessa percepção, o próprio direito teve que ser estendido para dar conta da nova esfera de vida que clamava por reconhecimento.

Percebeu-se, assim, que as leis existentes, de difamação e de direitos autorais já não bastavam para dar conta dos novos sentidos que o privado vinha assumindo. Em relação ao primeiro caso, argumentam os juristas: "não é contra a violação do caráter individual que a prevenção se faz necessária, mas contra a violação da privacidade. (...) O direito de privacidade proíbe não apenas que se faça um retrato incorreto da vida 
privada (que seria difamação), mas sim que qualquer retrato dela seja feito" (Warren; Brandeis, 1890, p. 9, tradução minha).

De modo análogo, a privacidade também seria diferente dos direitos de propriedade intelectual, já que a lei de copyright poderia proteger a publicação de uma carta, mas não a divulgação dos fatos privados contidos nela. O que ocorreria então, se alguém recebesse uma carta sobre a qual nenhum direito de propriedade intelectual tenha sido registrado? Ela poderia publicá-la, ou divulgar seu conteúdo? A resposta, para os juristas, é negativa: "A obrigação é simplesmente observar o direito legal do remetente, (...) seja ele chamado seu direito de propriedade dos conteúdos da carta, ou seu direito de privacidade" (idem).

Desse modo, o direito de privacidade emerge com um sentido adicional em relação à ideia de propriedade simples, e que reside, fundamentalmente, no fato de que suas prerrogativas não emergem do contrato ou de confiança especial, mas são "direitos contra o mundo" (ibid.). A partir deles, reconhece-se a existência de uma esfera que é propriedade do indivíduo, mas cujo sentido principal é o de estar em oposição ao mundo, e que, portanto, deve ser "deixada em paz".

Vemos, portanto, que a privacidade emerge com dois sentidos fundamentais: como a propriedade tradicional do indivíduo sobre a casa e a personalidade, e como esfera de existência contra o mundo. A insistência dos autores em mostrar a diferença entre ambos e estabelecer o último como a singularidade da privacidade mostra claramente que a casa já não era mais entendida como simples propriedade e que sua existência agora adquiria um novo sentido, separado da esfera da reprodução material e do espaço público em geral.

Porém, há que se notar que, junto ao desenvolvimento de uma nova forma de vivência do espaço privado, isto é, a intimidade burguesa, como veremos na próxima sessão, os autores observam uma outra tendência, 
que a princípio parece colidir com essa nova forma de vida. Não é senão em razão da progressão dos negócios - a partir da qual se começa a vislumbrar valor monetário nos produtos da vida espiritual do homem - que o direito de privacidade vem a se manifestar. Seu sentido mais agudo, portanto, é o da materialização do desejo de que a esfera doméstica, por sua importância própria ao modo de vida burguês, fosse legalmente protegida da intrusão da esfera econômica, representada pelos negócios e pelo trabalho.

\section{A casa como "lar": a vida privada burguesa no primeiro espírito do capitalismo}

A concepção de um âmbito doméstico separado das outras esferas de existência é, portanto, o ponto de partida para o surgimento da privacidade como direito. Esse desejo de intimidade, de uma esfera de segredo e isolamento é facilmente vislumbrado a partir das transformações das funções da casa em boa parte do Ocidente. Na Europa do século XVIII, por exemplo, como mostra Rybczynski (1987), a maioria das casas não possuía como função exclusiva o abrigo e a proteção da família, mas funcionava como um espaço com múltiplas atribuições - sobretudo o trabalho - e no qual transitava grande número de pessoas. Além disso, antes do final do século XIX, as famílias pobres (cerca de metade de população da Inglaterra), viviam em um cômodo único e tinham que urinar, defecar e copular na frente dos outros (Stone, 1991). Nesses cenários, pode-se arguir que as condições básicas para a concretização da privacidade não estavam presentes.

Entretanto, nota-se já nesse período uma mudança determinante para que a privacidade pudesse emergir. $\mathrm{O}$ valor moral acentuado ao trabalho típico da ética protestante fez com que importância correlata fosse 
atribuída à família, já que ela era a unidade básica da produção (Zaretsky, 1976, p. 28). Além disso, principalmente entre os puritanos, a família possuía papel importante para o aprofundamento da autoconsciência e da percepção de uma vida interior, psíquica, necessária para a relação com Deus. A isto, soma-se o processo de socialização dos processos de produção de mercadorias, que remove o trabalho do âmbito dos esforços privados de famílias ou vilas e o centraliza nas unidades corporativas de larga escala (Zaretsky, 1976, p. 29). Ambos os processos foram fundamentais para a consolidação da divisão entre público e privado que separava a esfera do trabalho produtivo da vida familiar e conferia novos sentidos para a última.

Além de sua relação com o âmbito do sagrado, a família e a vida doméstica acompanham um movimento mais geral vinculado ao desenvolvimento do capitalismo industrial na Europa. Para os burgueses, isso significou uma separação nítida entre a esfera do trabalho e aquela em que deveria prevalecer a vida afetiva. Entre as classes trabalhadoras, o trabalho extenuante e mal pago nas fábricas (Engels, [1845] 1987) também faz com que o convívio familiar seja visto como um abrigo privado da dureza do mundo lá fora. Essa idealização elevou a família à condição de um lugar sagrado, o domínio do espírito em oposição ao domínio material da atividade produtiva e, portanto, o local privilegiado para o cultivo do eu e da intimidade, tão estimado pelos burgueses. Assim, ideais de autoconhecimento e de autorrealização começaram a tomar corpo na esfera privada, e foram estendidos, inclusive, aos trabalhadores, que também passaram a buscar sua felicidade nas relações pessoais e domésticas, fora da esfera do trabalho ou do mundo público.

Esse período, caracterizado por Boltanski e Chiapello (2009) como "primeiro espírito do capitalismo", tem como centro o burguês empreendedor, aventureiro e disposto a assumir riscos, mas, ao mesmo tempo, 
poupador, controlado, perito nas habilidades do cálculo e da racionalização das ações, combinadas com a "importância atribuída à família, à linhagem, ao patrimônio, à castidade das moças" (p. 49), bem como às relações paternalistas com empregados e à "caridade para aliviar o sofrimento dos pobres" (p. 50).

Esse amálgama de disposições aparentemente contraditórias de que falam os autores - "sede de lucro e moralismo, avareza e caridade, cientificismo e tradicionalismo familiar" (Boltanski; Chiapello, 2009, p. 50) - também foi observado por Franco Moretti em "O Burguês". A "paixão serena" dos burgueses, em oposição à "paixão turbulenta" da aristocracia e seu ethos guerreiro, refletia-se no cotidiano pacífico e repetível, na regularidade da vida privada tão prezada por essa classe. Assim, se a criação de uma cultura do trabalho foi, como mostrou Weber, a maior conquista simbólica da burguesia como classe, isso não significa a abolição de qualquer forma de desfrute, mesmo entre os protestantes.

A ideia do conforto doméstico ganha força no decorrer do século XVIII, principalmente entre os ingleses (Moretti, 2014). Diferente da extravagância do luxo, o conforto remete à necessidade de aliviar o cansaço do trabalho. O lar é, sobretudo, um lugar de descanso, logo, ele precisa ser confortável. É por essa aproximação com o trabalho que o conforto torna-se permissível, como aponta Moretti, para a ética protestante. Um conforto sóbrio que não desvirtua a vocação e que é fundamental para a recuperação das forças, para seguir adiante na labuta diária. Para isso, é preciso que a casa esteja fisicamente resguardada do mundo público, ou seja, é preciso que haja privacidade.

Entretanto, embora a privacidade esteja vinculada, desde o início, ao trabalho, isso não impede que a existência na esfera privada se desenvolva com uma tonalidade própria. Como escreveu um leitor acerca dos Buddenbrooks de Thomas Mann: "acontece tão pouca coisa que eu 
deveria ficar entendiado, mas não fico. (...). Como é que o cotidiano conseguiu se tornar interessante?" (Moretti, 2014, p. 86).

Uma vida criada aparte do olhar dos outros começou a materializar-se em vários âmbitos: na sociabilidade restrita entre os membros da família, na maior intimidade entre os casais, na criação de espaços para vivenciar a solidão, no uso de objetos que estimulavam o fortalecimento da individualidade, tais como diários, álbuns de fotos, espelhos e mais uma série de outros suportes para o desejo de afirmação da identidade individual. E assim, vemos surgir uma plêiade de novos sentidos para a esfera privada. O modo de vida burguês, com sua devoção à família, ao lar e a uma intimidade secretamente construída e preservada, deu origem a essa "descoberta maravilhosa que era a privacidade, necessidade para os ricos e aspiração para os pobres" (Gay, 1999, p. 315, tradução minha).

Assim, se em sua essência a vida privada, no primeiro espírito do capitalismo, não se desvincula do trabalho, seus sentidos certamente terminaram por ultrapassá-lo. Sobretudo por isso, a fruição da vida privada e seus prazeres, ainda que modestos, não deixa de se colocar em tensão com a ascese produtiva. Essa tensão permeará o espírito da época, o "século sério" (Moretti, 2014) e encontrará algum alívio com a assunção da sociedade de consumo típica do segundo espírito do capitalismo, como veremos a seguir, porém, apenas para dar lugar a novos conflitos e ambiguidades. 


\section{A privacidade no segundo espírito do capitalismo: da santidade do lar ao mercado}

Se a fase que dominou o capitalismo no século XIX e no primeiro terço do XX foi marcada pela poupança e sua moral de comedimento, controle, disciplina, restrição, labor, regularidade, perseverança e estabilidade (Bolstanski; Chiapello, 2009), na segunda, "eis um tipo de sociedade que substitui a coerção pela sedução, o dever pelo hedonismo, a poupança pelo dispêndio, o recalque pela liberação e as promessas do futuro pelo presente" (Lipovetsky, 2007, p. 35). Paradoxalmente, a figura emblemática dessa nova fase não é mais o capitalista aventureiro do primeiro espírito, movido pela ambição e pela inventividade. Ao contrário, o personagem-chave é agora o empregado, o burocrata que se submete às regras da organização e o diretor (ou dirigente assalariado) - e não mais o burguês proprietário (Lopez-Ruiz, 2004). A passagem do mundo da pequena propriedade e dos pequenos empresários para uma sociedade caracterizada pela propriedade concentrada e pelos empregados assalariados trouxe substantivas transformações ao modo de vida da época. Para entender esse espírito, é fundamental perceber de que modo forças aparentemente opostas - o hedonismo consumista, de um lado, e a contenção burocrática, do outro - se relacionam.

Não por acaso, o cenário que concentra a descrição do tipo ideal que emerge no segundo espírito se desloca de velho mundo para os Estados Unidos da América: o auge das grandes corporações e da sociedade de consumo de massa não se separa da emergência desse país como o pilar hegemônico do capitalismo nessa nova fase. Essa é a época do surgimento das grandes organizações, das sociedades anônimas, da planificação, do taylorismo, da gestão empresarial racional. O desenvolvimento do racionalismo econômico faz com que a organização se sobreponha ao indivíduo: o sistema adquire vida própria e funciona de modo quase 
autônomo. O homem, cuja função no trabalho passou a ser resumida como "aquele que dá corda ao relógio" (Lopez-Ruiz, 2004, p. 77), ou que simplesmente presta serviços a uma grande organização, vê ainda mais motivos do que seu predecessor para procurar a autorrealização na esfera privada, junto à família. É por isso que, nesse modelo, a separação iniciada na fase anterior, entre a pessoa do trabalhador e a força de trabaIho que ele vende no mercado - ou entre a vida privada e a profissional - é ainda mais marcante. Qualquer sinal de mistura entre esses domínios passa a ser fortemente criticada: patrões que favorecem parentes, ou levar em conta a vida privada, a moralidade ou a visão política do funcionário na hora da contratação (Boltanski; Chiapello, 2009).

A geração de burocratas e empregados apáticos e sem paixão pelo trabalho, que entregavam toda sua energia ao desfrute da vida suburbana, despertava preocupação nos pensadores da época. Acerca disso, escreveu Mills sobre a sociedade norte-americana, em 1951:

O evangelho do trabalho tem sido um aspecto essencial da tradição histórica americana (...). A crise e o declínio desse evangelho têm uma significação profunda. (...) a agressividade e o entusiasmo que marcaram as outras gerações está desaparecendo... Quando o trabalho não é mais do que trabalho, uma atividade realizada apenas por motivos de subsistência, o espírito que incentivou essa nação para sua grandeza atual já desapareceu. Uma apatia ameaçadora oculta o descontentamento e a impaciência dos quadros dirigentes de amanhã (Mills, 1969, p. 237-8).

Essa nova classe "não-burguesa", como chama o autor, não havia sido contagiada pela antiga ética do trabalho de sua antecessora. $\mathrm{O}$ trabalho para ela, separou-se das outras atividades da vida: todas as satisfações que a vida Ihes proporciona ocorrem fora dos limites do trabalho; trabalho e vida estão profundamente separados, dirá Mills, e isso complica grandemente a tarefa dos que dirigem e administram os processos produtivos. 
A vida dos empregados passou a ser preenchida com o desfrute das benesses do consumo de massa florescente. Na medida em que o salário havia tomado o lugar da propriedade produtiva como base econômica da família, a propriedade privada foi redefinida entre os trabalhadores para referir-se a mercadorias: comida, roupas, artigos domésticos e, mais tarde, à casa.

Acostumados ao discurso da sobriedade, do trabalho duro e da disciplina, os empregados tiveram de ser reeducados para o novo discurso centrado na apreciação de uma vida hedonista, com novos desejos e necessidades. A propaganda auxiliou sobretudo a corrupção dos velhos valores, contribuindo para o descrédito das noções puritanas de frugalidade, paciência, abstinência e moderação (Featherstone, 1991). O consumo nasceu, assim, como uma "máquina de tentações, um assalto à disciplina do eu, que prometia estimular os sentidos e trazer ao alcance do trabalhador comum uma vida extraordinária e confortável, capaz de diminuir sua fadiga" (Ehrenberg, 1995, p. 59). Aqui vemos novamente aparecer o conforto da casa para recuperação das energias gastas no trabalho, mas com uma diferença importante: se antes havia a preocupação com o comedimento e a frugalidade e o conforto na medida certa, agora a vida privada surge em meio a imagens oníricas criadas pela publicidade, povoadas por modelos de bom gosto e de uma vida excitante.

Assim, cada vez mais aspectos da vida privada foram sendo subsumidos à lógica mercantil: lazer e tempo livre, hobbies e outras experiências tornaram-se cada vez mais dependentes do mercado em expansão. Esse é um aspecto fundamental para se compreender a nova relação entre vida privada e sistema no segundo espírito do capitalismo. Se, em ambas as fases, a vida privada está intimamente ligada ao mundo do trabalho e é orientada por ele, a relação irá se construir de modo diferente em cada momento. A comparação feita por Lopez-Ruiz sintetiza muito bem essa 
diferença: ele lembra do exemplo dado por Weber (2004, p. 194) do veIho norte-americano que, apesar de rico e de idade avançada, encontrava-se inquieto e sem poder desfrutar da família por querer ampliar ainda mais a fachada de sua loja. O dia de domingo, para ele, não era mais do que uma fastidiosa pausa para retomar a luta para que sua loja fosse a maior da cidade (Lopez-Ruiz, 2004). O executivo sênior das grandes corporações, em contraposição, é movido pelos interesses da organização em que trabalha e os sonhos que o animam são "mais bons filés nas refeições, outros hotéis confortáveis para experimentar e mais voos em primeira classe" (idem, p. 144). No primeiro espírito, a oposição entre trabalho e família consagrava a esta um lugar de descanso, recuperação de forças e desfrute da intimidade. No segundo, já há claramente uma presença maior das forças econômicas externas na esfera privada: embora o burocrata pareça ser movido pela convivência familiar e pouca paixão demonstre pelo trabalho, há nesse estágio uma presença muito maior da esfera econômica em sua intimidade, que se revela na centralidade que as mercadorias adquirem em sua vida. Desse modo, embora a marcante separação entre trabalho e vida familiar pudesse nos levar para a direção oposta, isto é, a de que a esfera econômica estaria completamente ausente da esfera privada no segundo espírito do capitalismo, não devemos nos deixar confundir: se, no primeiro espírito, há a preocupação clara em proteger a esfera privada da intromissão das forças externas, incluindo as econômicas, no segundo, estas começam gradualmente a empurrar as barreiras protetoras e adentrar o espaço do lar.

Entretanto, se a emergente sociedade de consumo via na esfera privada um rico mercado fundamental para seu crescimento, a separação estrita entre vida pessoal e trabalho não vinha sendo benéfica para o capital. O trabalho não poderia ser mais apenas um meio de subsistência; era preciso que fossem mobilizados novamente o gosto pelo risco, pela 
aventura, a ambição e a devoção ao trabalho. A partir dessa percepção, os especialistas do mundo dos negócios passaram a empreender uma busca por novas justificações que apresentassem uma motivação para o esforço cotidiano no trabalho assim como um sentido para este (Lopez-Ruiz, 2004, p. 151). Como observa Mills, "para obter e aumentar a boa disposição para o trabalho é necessário criar uma nova ética que dê ao trabalhador outro incentivo além do econômico" (1969, p. 251).

Nessa toada, tiveram início os estudos de relações humanas na indústria, que procuravam uma forma de integrar a vida privada ao trabaIho. O sucesso das políticas distributivas do Estado e o fortalecimento dos sindicatos forçavam respostas do mundo corporativo às ameaças representadas pela resistência ao trabalho. A retórica das emoções, com o vocabulário benigno da comunicação, da empatia e da cooperação, apareceu como a resposta mais adequada a esse desafio, na medida em que não só neutralizava as tensões, como era capaz de engajar novamente o trabalhador por inteiro - de corpo e alma - aos seus processos. Veremos como, no terceiro espírito do capitalismo, esse engajamento será um aspecto determinante para entender a aproximação entre vida privada e economia.

Espaços de transição e fronteiras em movimento: aproximações entre o público e o privado

A transição para o terceiro espírito do capitalismo e para um novo desenho da relação entre público e privado não se deu sem que houvesse espaços de transição entre um tipo de vivência e outro. O bairro, por exemplo, que sempre fora visto como um espaço semipúblico, no qual as pessoas se encontravam e se conheciam, começa a adquirir um novo significado a partir das inovações arquitetônicas modernas. Com o aumento 
das distâncias criadas pelos grandes prédios e conjuntos habitacionais, o convívio próximo com os vizinhos passa a ser mais escasso e o bairro torna-se um local de pessoas estranhas, sobretudo nas grandes metrópoles (Prost; Vincent, 1992).

As casas tornam-se cada vez mais isoladas e protegidas das ruas, com aumento do recuo frontal que as separa do espaço público, garantindo também que os passantes não saibam o que acontece intra-muros. Se esse distanciamento proporcionou a libertação das amarras da censura, da maledicência e da vigilância alheias, com ele os habitantes dos grandes centros urbanos eliminaram progressivamente o aspecto pessoal das zonas de transição. Mesmo nos espaços de convívio mais próximo, como mercados, cafés e bares do bairro, a sociabilidade torna-se mais distante, por um lado, e menos intrusiva, por outro.

No ambiente profissional, entretanto, as mudanças dão-se no sentido oposto: se os grandes prédios isolavam os habitantes da cidade e solapavam as relações pessoais nos bairros, em âmbito profissional as relações começaram a tornar-se cada vez mais pessoalizadas. "Ilhas de sociabilidade informal" surgem nas cantinas e cafés das empresas, onde se permite que haja conversas longe dos ouvidos dos superiores (Prost; Vincent, 1992, p. 128) e a sociabilidade com os colegas de trabalho começa a tornar-se mais próxima, mediante tentativas de restabelecer relações pessoais dentro do ambiente rígido das organizações.

Desse modo, a vida privada, expulsa do universo coletivo e público do trabalho, torna a ingressar nele de maneira discreta e gradativa. Nos anos 1950 e 1960, começaram a se tornar populares as teorias da gestão emocional (Illouz, 2007), que pregavam uma aproximação entre líderes e subordinados, em vez da gestão fria e distante típica das grandes organizações. Essas teorias baseavam-se em estudos, como os de Elton Mayo na General Eletric, que mostravam que a maior atenção dada aos senti- 
mentos dos trabalhadores poderia aumentar significativamente sua produtividade. Com efeito, a retórica das emoções, baseada no repertório da terapia, tornou-se presente tanto nas estratégias produtivas das empresas, como na gestão dos conflitos e das relações entre os empregados (idem). É importante ressaltar essa passagem, pois ela registra o preciso momento em que se percebe que a vida pessoal poderia dar bons frutos, quando incorporada devidamente ao processo produtivo. Essa incorporação sinaliza que a existência em dois domínios distintos começa a se enfraquecer, e que a vida privada, nesse momento, adquire um novo significado.

\section{A vida privada no capitalismo conexionista}

Neste ponto nos aproximamos de compreender as razões pelas quais a privacidade, tal como experimentada no primeiro e segundo espíritos do capitalismo, torna-se uma relação sem lugar no capitalismo conexionista. Uma série de mudanças dão início a essa nova configuração valorativa identificada por Boltanski e Chiapello (2009). Seu grande marco simbólico são as revoltas ocorridas em maio-junho de 1968 na França, que desferiram um golpe mortal no segundo espírito do capitalismo, desacreditando suas formas de justificação como arcaicas, autoritárias e irreais. A confluência entre as críticas estética e social ${ }^{3}$ que aparece nessa crise promove uma contestação geral dos pilares que organizam o antigo espírito: o descrédito na possibilidade de construir uma carreira estável, a crescente exploração do trabalho promovida pela reestruturação produtiva, o descontentamento com a impessoalidade, a frieza e a rígida hierarquia das grandes organizações racionalizadas, a inautenticidade, a perda

3 A crítica estética, simbolizada pelas revoltas de 1968, corresponde a uma demanda por liberdade em relação às formas hierárquicas e burocratizadas, e ao clamor por autenticidade como reação à massificação característica das grandes sociedades industrializadas. A crítica social, por sua vez, articulada pelos movimentos trabalhadores, centrou-se nas demandas sociais, principalmente na concessão de melhores salários e condições de trabalho. 
de autonomia, a falta de criatividade e diferentes formas de opressão do mundo moderno. Na esfera do trabalho e da produção, predomina a crítica "ao 'poder hierarquizado', ao paternalismo, ao autoritarismo, aos horários impostos, às tarefas prescritas, à separação tayloriana entre concepção e execução" (Boltanski; Chiapello , 2009, p. 200-1).

Um dos pontos-chave do livro é mostrar como essas críticas foram desarmadas pelo capitalismo conexionista, a partir da incorporação de seus diversos pilares ao próprio sistema. Assim, se nos anos 60, temia-se qualquer presença de laços familiares entre os empregadores que pudessem comprometer a racionalidade ou objetividade da administração, a literatura gerencial da década de 1990 rejeita quaisquer sinais de hierarquia ou controle de cima para baixo (Budgen, 2000, p. 152). Além disso, ela confere um lugar completamente diferente para a vida pessoal. A crítica à inautenticidade e às formas rígidas hierárquicas é respondida com uma mudança dos princípios gerenciais, que trazem para o centro da cena as qualidades e méritos pessoais dos funcionários. Estes, também passam a ser avaliados de modo individualizado, a partir de seu desempenho e produtividade, que são considerados como parte indissociável de suas qualidades pessoais. Dessa forma, o envolvimento dos indivíduos nos projetos do mundo conexionista depende diretamente de suas qualidades pessoais - o modo como se relaciona com os pares, autonomia, empreendedorismo, iniciativa, flexibilidade (para trabalhar em múltiplos projetos), comunicabilidade, equilíbrio psicológico (capacidade de suportar pressão), sociabilidade (para fazer contatos), entre tantas outras características que devem ser cultivadas e reveladas oportunamente. Essas qualidades serão utilizadas como medida de valor para julgar competências e méritos; elas criarão um repertório, uma linguagem, que transpassará o âmbito das corporações e irá se instalar em outras esferas. 
No que diz respeito aos pilares morais que estruturam esse espírito, há uma transformação significativa em relação à propriedade. A relação entre esta e o poder, dissociada no segundo espírito, adquire a forma da locação ou disponibilidade plena, mas temporária. Diferente do proprietário dependente da posse e do diretor dependente da organização, há o colaborador que "toma as coisas de empréstimo" e dispõe das pessoas e dos recursos durante o tempo que Ihe convém (Boltanski; Chiapello, 2009, p. 191). A informação, recurso fundamental desse sistema, assume também a forma da locação, sendo emprestada e recombinada conforme as necessidades ad hoc que os projetos criam. Mas isso não significa que a cidade por projetos ${ }^{4}$ e o mundo em rede ignorem a posse. Ao contrário, ela "leva ao extremo um elemento que esteve na origem da concepção liberal de propriedade: o homem como proprietário de si mesmo, não se-

${ }^{4}$ O termo em francês utilizado pelos autores é cité par projets. Para compreender o conceito de "cidade", há que se retomar algumas noções que embasam o pensamento de Boltanski e Chiapello. O mote que inicia a argumentação dos autores é a constatação de que o capitalismo é um sistema que em si próprio não contém as razões para explicar o engajamento dos atores em sua ordem, já que seu maior objetivo é acumulação per se, o que não explicaria a aceitação pacífica da subordinação a suas regras. Para que o engajamento ocorra é preciso haver boas justificativas. De Max Weber, eles tomam a ideia de que os homens são imbuídos por razões morais fortes para aderir às regras, entretanto, essas razões, manifestas no nível individual, não seriam suficientes. Então, Boltanski e Chiapello tomam de A. Hirschman uma segunda fonte de justificação que se manifesta em termos do "bem comum". O espírito do capitalismo passa a não ser mais definido por um conteúdo substantivo, um ethos, mas sim, por um conjunto de crenças associadas com a ordem capitalista, que ajuda a justificar e legitimar essa ordem, configurando os modos de ação e as disposições que são coerentes com ela. De Weber os autores também tomam a ideia de uma dupla racionalidade em ação para que o sistema opere: aquela orientada para os fins do lucro, e uma racionalidade orientada por valores: um ator que julga em nome de princípios universais. $\mathrm{O}$ acordo sobre esses princípios universais é uma convenção geral orientada para o bem comum e se pretende como universalmente válida. É essa a ideia por trás do conceito de "cidade", que engloba os atores e objetos que a habitam, assim como os acordos que possibilitam estabelecer equivalências suscetíveis de superar as particularidades das pessoas e coisas. Esses acordos são convenções que devem fazer sentido para todos, são orientados por uma ideia de justiça, e se pretendem universalmente válidos. Eles garantem uma ordem estável na qual o conflito entre desiguais pode existir sem que a ordem geral seja ameaçada. Para mais detalhes, ver: Sociologie générale », L'Année sociologique 1/2001 (Vol. 51) , p. 257-273 URL: www.cairn.info/revue-l-annee-sociologique-2001-1-page-257.htm. 
gundo um direito natural, mas no sentido de ser produto de seu próprio trabalho sobre si mesmo" (Boltanski; Chiapello, 2009, p. 191-2). Prova disso é o crescimento das indústrias que cuidam da autoimagem: moda, saúde, estética, cosmética, coaching, etc. Nessa lógica, a propriedade está, sobretudo, vinculada a uma responsabilidade sobre si: "cada um, sendo produtor de si mesmo, é responsável por seu corpo, sua imagem, seu sucesso, seu destino" (idem, p. 192). Por outro lado, o homem proprietário de si mesmo o é de modo muito peculiar, já que sua vida privada deixa de ser sua propriedade exclusiva e passa a ser apropriada pelo mundo do trabalho e pelo mercado como um todo. Esse é um aspecto-chave para entendermos como a vida privada tornou-se, no limite, algo passível de ser comercializado ${ }^{5}$. Ao perder a proteção que a imunizava contra as investidas do mundo público, a vida privada pode ser objeto de todo tipo de apropriação.

O empreendedor de si mesmo sabe que o sucesso e a posse das características valorizadas pelo mundo em rede não são um dado genético. É preciso cultivá-las para desenvolver os recursos internos individuais e assim garantir uma boa imagem de si. Esta, por sua vez, resulta em boas

\footnotetext{
5 Sabe-se que boa parte da inteligência de mercado, hoje, é baseada no conhecimento que se tem dos consumidores: como vivem, o que fazem, do que gostam. Com as redes sociais, essas informações tornaram-se abundantes. Assim, as ações de marketing modernas envolvem a apropriação (ou compra) - quase sempre legal, vale frisar - de informações relativas à vida privada dos usuários de redes sociais que são automaticamente cedidas por eles no momento em que criam um perfil e aceitam os termos de uso do site. Tornou-se prática comum entre as agências e departamentos de marketing o monitoramento contínuo de grupos de usuários alvo de alguma ação de mercado. Definem-se perfis de consumo e a partir deles monitora-se toda a rotina dos usuários-consumidores selecionados nas redes por um período que pode durar meses, para que o mercado possa entender o que determinado "segmento" deseja e antecipá-lo no lançamento de produtos e campanhas publicitárias. Na outra ponta dessa engrenagem encontram-se usuários que "investem" na exibição de suas vidas para obter um maior número de seguidores. O grande número de seguidores as classificam, no mercado, como "influenciadores", e atrai empresas interessadas em divulgar produtos, assim como garante notoriedade em determinado campo profissional. Como exemplo, há os perfis no Instagram, no Snapchat e nos canais do YouTube que visam divulgar estilo de vida e o trabalho de determinadas pessoas (observe-se que trabalho e estilo de vida são apresentados juntos): fashionistas, chefs de cozinha, artistas, médicos, bodybuilders, etc.
} 
redes, boas conexões e amplo reconhecimento. Entretanto, ele também sabe que apenas o cultivo das qualidades individuais não é suficiente. Nesse ponto, é possível estabelecer mais claramente a relação entre o capitalismo conexionista e as NTICs. Embora os autores não realizem essa conexão de modo explícito no livro, ela certamente pode ser aventada, na medida em que as afinidades são claras e já percebidas por outros autores $^{6}$. As redes sociais, por exemplo, têm papel evidente como vitrine para a apresentação do eu e para a exibição das características "certas", dos sinais de sucesso, que garantirão a ampliação das conexões e o reconhecimento dos pares. Como afirmam Boltanski e Chiapello sobre o networker (ou redeiro), o tipo ideal bem-sucedido desse sistema, é preciso que, "no fim de um projeto, algo lhe seja atribuído e publicamente associado a seu nome" (2009, p. 368). Sem esse último passo, isto é, sem a publicização dos feitos, das realizações e dos atributos que constituem as provas, o exercício não está completo. A apresentação do eu nesses ambientes seria pautada pelo gerenciamento cuidadoso dos símbolos que conferem status, respondendo à demanda de adaptação dos selves ao universo simbólico do capitalismo conexionista. A capacidade de ser bem-sucedido dependeria da exibição correta dos símbolos de sucesso da cidade por projetos e seria o caminho para aumentar a rede de contatos e amigos, um dos maiores sinais de aprovação que o indivíduo pode ter.

Levar esse aspecto em conta é fundamental para compreender as possibilidades de resistência ou adesão e engajamento às regras desse jogo. Embora a exposição da vida privada se oponha ao princípio de resguardo dessa esfera da vida que é o cerne da privacidade, esse tipo de prática tornou-se um fenômeno praticamente ubíquo de norte a sul do globo, e cada vez mais presente entre as novas gerações. Isso nos direcio-

${ }_{6}^{6}$ Ver, por exemplo, o artigo de Carla Rodrigues (2010), em que a autora explora as afinidades entre o "capitalismo informacional" e a manifestação de suas "exigências profissionais" nas redes sociais. 
na para o ponto que parece fazer mais sentido, isto é, que estar presente nesses ambientes e realizar a contento o gerenciamento de si nessas redes pode render bons frutos, assim como estar ausente deles pode gerar um custo social alto. Um estudo recente feito pelo Pew Research Center, por exemplo, mostrou que os jovens se sentem desgastados com o excesso de informações compartilhadas nas redes sociais, mas continuam a utilizar a rede porque ela é crucial para sua vida social. A antropóloga Ilana Gershon (2011) constatou, em sua pesquisa com estudantes da Universidade de Indiana, que muitos se mostravam descontentes com o Facebook, por acreditarem que a rede os transformava em pessoas ciumentas, invejosas e competitivas, além de prejudicar seus relacionamentos. Para a pesquisadora, os sentimentos relatados pelos estudantes eram sintomas da transposição de "princípios neoliberais" aos selves dos jovens. O Facebook os encoraja a se apresentarem como um "conjunto flexível" de habilidades, traços úteis e gostos (de consumo) que precisam ser constantemente aprimorados" (p. 867), bem como a se engajarem em relações do tipo "neoliberal", conexões fracas e funcionais a serem ampliadas constantemente. Uma de suas entrevistadas afirmou: "Você tem de apresentar a foto perfeita no perfil, que deve ser atualizada pelo menos uma vez em poucos meses. Se você não o fizer, você é um loser" (Gershon, 2011, p. 877). Outra entrevistada deixava claro como se sentia competitiva em relação a uma garota de quem suspeitava estar paquerando seu namorado:

Eu tenho mais amigos do que ela no Facebook, mais amigos que ativamente escrevem na minha página e mais fotos do que ela, então sou uma cyber-persona mais popular, embora, na verdade, eu seja uma eremita. Moro sozinha e tenho um cachorro. Não saio, de fato, com essas pessoas. Mas parece que saio (Gershon, 2011, p. 878).

Os entrevistados de Gershon também relataram que é comum universidades e potenciais empregadores checarem as redes sociais de can- 
didatos à procura de informações sobre os mesmos, daí que o investimento na criação e manutenção da rede social seja muito alto. Uma pesquisa realizada pela empresa CareerBuilder descobriu que pelo menos 2 em cada 5 companhias procuram informações online sobre seus candidatos para avaliar seu "caráter e personalidade". Assim, a demonstração de uma "personalidade interessante", com habilidades comunicativas e boas redes auxiliaria na contratação, enquanto informações inapropriadas, ou um perfil pouco atrativo desestimularia a seleção do candidato. Outras razões para a desistência da contratação seriam a demonstração de poucas habilidades comunicativas na página, a difamação de antigos empregadores, ou comentários ofensivos relacionados a gênero, etnia ou religião. A Forbes também alerta que um candidato "silencioso" está em desvantagem: a ausência de informações online pode ser interpretada como suspeita, ou como inabilidade do candidato em estabelecer conexões e se comunicar de modo positivo ${ }^{7}$.

Daí que a exibição da vida pessoal nas redes sociais e em outros âmbitos possa ser vista a partir de um duplo processo: de um lado, quando bem realizada, revela as qualidades prezadas pelo mundo conexionista e gera bons frutos ao indivíduo bem ajustado, sejam eles financeiros, sociais (mais amigos e conexões), ou simbólicos (fama e reconhecimento). De outro, proporciona informações que movimentam o sistema, sobretudo, às empresas de tecnologia que se valem diretamente dos dados pessoais como insumo de seus negócios.

Conforme apontado no início do artigo, o sentido primordial da privacidade estava vinculado à propriedade do indivíduo sobre sua vida privada, a qual deveria ser protegida das intromissões do mundo público. No capitalismo conexionista, essa propriedade tem seu escopo reduzido e limita-se às qualidades pessoais, ao patrimônio individual de cada um.

7 Jacquelyn Smith. "How Social Media Can Help (Or Hurt) You In Your Job Search". Revista Forbes. 16 de abril de 2013. 
Este, por sua vez, deve ser capitalizado, portanto, não faz sentido que seja mantido a sete chaves e distante dos domínios em que seu rendimento é possível. Em termos concretos, isso significa dizer que a privacidade, em muitos contextos, pode tornar-se um obstáculo para desfrutar dos benefícios que a exibição bem-sucedida da vida privada oferece, seja em forma de dinheiro, fama ou algum tipo de reconhecimento.

\section{Conclusão}

A separação crescente entre a esfera doméstica e a esfera profissional, assim como entre a pessoa do trabalhador e sua força de trabalho vendida no mercado é típica da formação do capitalismo desde seus primórdios, conforme observou Max Weber. O mundo burguês fez de tudo para que a esfera de vida doméstica, transformada em "lar", fosse protegida da intrusão do público em seus diversos aspectos. Essa proteção, como vimos, foi desafiada ao longo das transformações dos espíritos do capitalismo e, ao menos desde a década de 1970, é possível reconhecer um processo claro em direção a uma interpenetração cada vez maior entre vida privada e esfera econômica, que certamente é potencializada pela disseminação das tecnologias da informação, mas não consequência dela.

Assim, conforme os valores e as justificações que animam o capitalismo conexionista se estabelecem, nota-se a progressiva transformação dos contornos da esfera privada. Se, para os burgueses, a intromissão do mundo público na esfera privada era ilegítima e condenável, no terceiro espírito do capitalismo a vida privada pode ser legitimamente apreendida pela esfera econômica em razão das transformações nas formas de justificação da cidade por projetos. Conforme o foco da atenção se desvia dos processos - na organização burocrática - para a produtividade individual, a própria personalidade do indivíduo, antes relaciona- 
da à vivência privada, torna-se, no capitalismo conexionista, um asset a ser capitalizado no mercado. Etapa fundamental dessa capitalização é constituída pela exibição de si nas redes sociais. Esse artigo pode ser resumido como uma tentativa de pensar e articular essas transformações para entender o sentido que assumem no presente. Ao que tudo indica, essas transformações caminham na direção da expansão do capital em direção a espaços antes inabitados por sua lógica: o lar, a intimidade, a personalidade e a vida pessoal.

Mariana Zanata Thibes é Doutora em Sociologia pela Universidade de São Paulo, com pós-doutorado pelo Programa de Ciências Humanas e Sociais da Universidade Federal do ABC.\mthibesster@gmail.com

\section{Referências}

1. BOLTANSKI, L.; CHIAPELLO, È. O Novo Espírito do Capitalismo, trad. Ivone C. Beneditti, São Paulo: Martins Fontes, 2009.

2. BUDGEN, S. A New "Spirit of Capitalism". New Left Review, v. 1, jan/fev, 2000, p.149-56.

3. DU GAY, P.; MORGAN, G. (eds.). New Spirits of Capitalism? Crises, Justifications and Dynamics. Oxford: Oxford University Press, 2013.

4. EHRENBERG, A. L'individu incertain. Paris: Calmann-Lévy, 1995.

5. ENGELS, F. The Condition of The Working Class in England. Londres: Penguin Books, [1845] 1987.

6. FEATHERSTONE, M.; HEPWORTH, M.; TURNER, B. S. The Body: Social Process and Cultural Theory. Londres: Sage Publications, 1991.

7. GAY, P. The Bourgeois Experience: Victoria to Freud, v. 1: Education of the Senses. Nova York: W. W. Norton \& Company, 1999.

8. GERSHON, I. Un-friend my heart: Facebook, Promiscuity, and a Heartbreak in a Neoliberal Age. Anthropological Quarterly, v. 84, n. 4, 2011, p.865-94.

9. HIRSCHMAN, Albert O. The passions and the interests: political arguments for capitalism before its triumph. Princeton: Princeton University Press, 1977. 
10. ILLOUZ, E. Cold Intimacies: The Making of Emotional Capitalism. Cambridge: Polity Press, 2007

11. LIPOVETSKY, G. A felicidade paradoxal: ensaios sobre a sociedade de hiperconsumo. São Paulo: Companhia das Letras, 2007.

12. LOPEZ-RUIZ, O. O ethos dos executivos das transnacionais e o espírito do capitalismo. Tese de doutorado. Unicamp, 2004.

13. MILLS, C. W. A nova classe média [White Collar]. 1. ed. Rio de Janeiro: Zahar Editores, 1969. 380 pp.

14. MORETTI, F. O burguês: entre a história e a literatura. São Paulo: Três Estrelas, 2014.

15. PIERUCCI, Antônio F. Apresentação. In: WEBER, M. A ética protestante e o "espírito" do capitalismo; tradução José Marcos Mariani de Macedo; revisão técnica de Antônio Flávio Pierucci. São Paulo: Companhia das Letras, 2004.

16. PROST, A.; VINCENT, G. (orgs.). A história da vida privada, v. 5: da Primeira Guerra a nossos dias. São Paulo: Companhia das Letras, 1992.

17. RYBCZYNSKI, W. Home: A Short History of an Idea. Nova York: Penguin Books, 1987.

18. RODRIGUES, C. Capitalismo informacional, redes sociais e dispositivos móveis: hipóteses de articulação. Revista Galáxia, São Paulo, n. 20, p. 70-83, dez. 2010

19. SENNET, R. The Fall of Public Man. Londres: W. W. Norton \& Company, 1977.

20. SENNET, R. The corrosion of character: the personal consequences of work in the new capitalism. Londres: W. W. Norton \& Company, 1998.

21. SEVCENKO, N. A capital irradiante: técnica, ritmos e ritos do Rio. In: SEVCENKO, N. (Org.). História da vida privada no Brasil, v. 3: da Belle Époque à era do rádio. 3 ed. São Paulo: Companhia das Letras, 1998, p. 513-619.

22. STONE, L. The Public and the Private in the Stately Homes of England, 15001990. Social Research, v. 58, n. 1, p. 227-51, 1991.

23. WARREN, S.; BRANDEIS, L., The Right to Privacy. Harvard Law Review, v. 4, n. 5. 193, 1890.

24. WEBER, M. A ética protestante e o "espírito" do capitalismo; tradução José Marcos Mariani de Macedo; revisão técnica de Antônio Flávio Pierucci. São Paulo: Companhia das Letras, 2004.

25. ZARETSKY, E. Capitalism, the Family, and Personal Life. Nova York: Harper \& Row, 1976.

Recebido: 24.08.2016

Aceite final: 10.10.2016 